\title{
The Influence of Synthesis Methods Against Anti-Cancer Activity of Curcumin Analogous
}

\author{
Imanuel Berly Delvis Kapelle ${ }^{1,2}$, Tun Tedja Irawadi ${ }^{3}$, Meika Syahbana Rusli ${ }^{2}$, \\ Djumali Mangunwidjaja ${ }^{2}$, Zainal Alim Mas'ud ${ }^{3}$ \\ ${ }^{1}$ Chemistry Department, Mathematic and Natural Science Faculty, Pattimura University, Maluku, Indonesia \\ ${ }^{2}$ Agricultural Industry Technology Department, Agriculture Technology Faculty, Bogor Agricultural Institute, Bogor, Indonesia \\ ${ }^{3}$ Chemistry Department, Mathematic and Natural Science Faculty, Bogor Agricultural Institute, Bogor, Indonesia
}

\section{Email address: \\ berly_mollucas@yahoo.com (I. B. D. Kapelle)}

\section{To cite this article:}

Imanuel Berly Delvis Kapelle, Tun Tedja Irawadi, Meika Syahbana Rusli, Djumali Mangunwidjaja, Zainal Alim Mas'ud. The Influence of Synthesis Methods Against Anti-Cancer Activity of Curcumin Analogous. Cancer Research Journal. Vol. 3, No. 4, 2015 , pp. 68-75.

doi: $10.11648 /$ j.crj.20150304.12

\begin{abstract}
Activity anticancer of curcumin analogous influenced by the structure, substituent and geometric isomeric. The purpose of this research was to determine the influence of curcumin analog synthesis methods against anti-cancer activity. The value of $\mathrm{IC}_{50}$ tested in vitro against breast cancer cells T47D uses the MTT method for samples aks $(1,5$-bis-benzo[1.3]dioxol5-yl-penta-1,4-dien-3-one) with a method of the process of microwave $257,798 \mu \mathrm{g} / \mathrm{ml}$ better than conventional method $555,276 \mu \mathrm{g} / \mathrm{ml}$. The results $\mathrm{IC}_{50}$ for samples akas (5-benzo 1.3 dioxol-5-yl-1-phenyl-penta-2,4-dien-1-one) with a method of microwave $7,247 \mu \mathrm{g} / \mathrm{ml}$ better than conventional method 125,300 $\mu \mathrm{g} / \mathrm{ml}$. Microwave method produces a product with a lower melting point and provide the results of anti-cancer activity against breast cancer cells T47D.
\end{abstract}

Keywords: Anticancer Activity, In Vitro, curcumin analogous

\section{Introduction}

Analogous compounds (homologous) curcumin is a compound that has properties pharmacological of the same or even better compared to the parent compound [1]. Curcumin compounds are cancer drugs from natural materials which have been reported to have anti-cancer activity of ginger $[1,2]$. Curcumin and curcumin analogous to have biological activity as anti-inflammatory, antioxidant, antitumor, and anticancer drug $[3,4,5,6,7]$. Activity of each compound is influenced by differences in functional groups and structures that affect the physical-chemical properties and pleiotropic effects [8]. Some analogues of curcumin with different substituent at the test activity in vitro and in vivo pharmacokinetics showed that the stability of analog monocarbonyl enhanced and the pharmacokinetic profile has also increased significantly [9]. curcumin structure reacted with several molecules and give effect as anti-cancer and it is done with chemotherapy [10].

Curcumin analogues bis-1,7- (2-hydroxyphenyl) -hepta1,6-diene-3,5-dione as an anti-cancer effect intestine by using radiation. Active side of curcumin analogues that provide those results are phenolic and conjugated double bonds [11]. Concentrations of curcumin analogues greatly affect the in vitro study using radiation $\gamma$, curcumin analogues prevent the loss of antioxidants, enzymatic and non-enzymatic as GSH [12]. Active group as an anti-inflammatory is cyclohexanone, which can improve the bioactivity [9]. Based on data from screening, quantitative structure activity relationships, indicates that the substituent having electron-withdrawing properties in the benzene ring greatly affect the antiinflammatory properties, two of the most active curcumin analog is that having substituents $\mathrm{F}$ and epoxide [13]. Active side of curcumin analogues which shows breast anticancer activity is carbon atom on a phenol group [14].

Curcumin analog synthesis procedures are generally performed using two conditions, namely the reaction and the acidic conditions alkaline conditions [15] and the reaction process can be accelerated by using microwave radiation at $160 \mathrm{~W}$ for $60-120 \mathrm{~s}$ [16]. Synthesis process can affect the purity, physical and chemical properties of the product. There are differences in activity between the isomers; one isomer 
having pharmacological activity, while others is virtually inactive. Differences in pharmacology work between the two enantiomers can be immense $[17,18]$, so the purpose of this study was to determine the influence of analog synthesis process curcumin against anti-cancer activity in vitro against breast cancer cells T47D.

\section{Material and Methods}

\subsection{Material}

Curcumin analogues synthesized product (AKS and AKAS), RPMI, aquabidest, $\mathrm{NaHCO}, \mathrm{NaOH}, \mathrm{HCL}, \mathrm{FBS}$, penisilinn-streptomycin, T47D cells,

\subsection{Manufacture of Culture Medium}

RPMI medium prepared in the following manner: RPMI powder was dissolved in $950 \mathrm{ml}$ of aquabidest sterile. Added 2.2 grams of $\mathrm{NaHCO} 3$ and stir until blended. Added akuabidest sterile until the volume of $1000 \mathrm{ml}$, stirring with a magnetic stirrer and added $1 \mathrm{~N} \mathrm{NaOH}$ or $\mathrm{HCl} 1 \mathrm{~N}$ to get medium without serum at $\mathrm{pH} 7.4$ which is the optimum $\mathrm{pH}$ of cell growth. Media sterilized by filtration through a micro filter size of $0.2 \mu \mathrm{m}$. The media are generally divided into $100-200 \mathrm{ml}$ volumes and stored at $4{ }^{\circ} \mathrm{C}$ to avoid damage and contamination. RPMI medium-serum created by: $100 \mathrm{ml}$ medium RPMI plus $10 \mathrm{ml}$ of fetal bovine serum (FBS), $1 \mathrm{ml}$ penicillin-streptomycin.

\subsection{Preparation of Cells}

T47D cells are inactive in the ampoule container (cryo tube) taken from a tank of liquid nitrogen or from the freezer $-80^{\circ} \mathrm{C}$ and immediately defrost at room temperature until the proper melt, then sprayed ampoule with 70\% alcohol. Ampoule is opened and the cell suspension was transferred dropwise into a sterile conical tube containing culture media (MK) with a micropipette $1000 \mu \mathrm{l}$. The cell suspension centrifuged $600 \mathrm{rpm}$ for 5 minutes, and then part supernatant disposed. Added $4 \mathrm{ml}$ of MK and suspended slowly until homogeneous using a pipette. Cells were observed with a microscope and incubated in an incubator at $37{ }^{\circ} \mathrm{C}$ with $5 \%$ $\mathrm{CO} 2$ stream. After 24 hours, the media was replaced and cells grown again until confluent and the amount are enough for the research.

\subsection{Replacement of Media}

Old media is slowly removed by micropipette or Pasteur pipette. $3 \mathrm{ml}$ of PBS inserted into tissue culture dish containing cell and tissue culture dish shake it to the right and to the left to wash the cells. Afterwards, PBS disposed with a micropipette or Pasteur pipette. Put 5-7 ml MK new into the tissue culture dish containing cells, homogenized, and observed conditions and the number of cells on an inverted microscope. Incubated overnight and replaced MK if the color of the media has changed.

\subsection{Harvest Cells}

After a sufficient number of cells ( $80 \%$ confluent), the medium removed by micropipette or Pasteur pipette, cell colonies were washed with PBS 2 times. Added trypsinEDTA ( $0.25 \%$ trypsin) evenly and incubated in an incubator for 3 minutes. Next, add $5 \mathrm{ml}$ new MK to inactivate trypsin. Suspended cells into the medium and then transferred into a sterile conical tube. After that, the cells were counted using a hemocytometer.

\subsection{Calculation of the Cell}

Cell count can be done in the following way: $10 \mu \mathrm{l}$ cell suspension is placed on a hemocytometer. Then the cells were counted on a hemocytometer under a microscope with a counter. The number of cells per $\mathrm{mL}$ can be calculated using the formula:

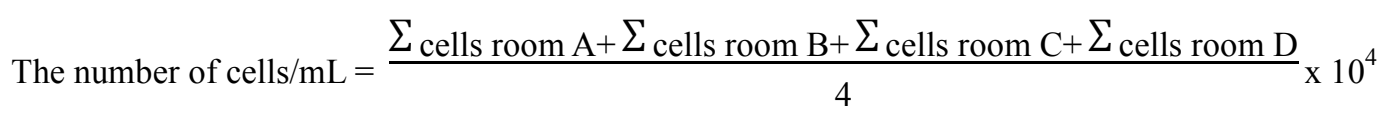

Cells that will be planted on the plate displacement required number of cells into a new conical tube and added
MK in accordance with the desired concentration. The volume of cell harvest that required calculated using formula:

$$
\text { Cell harvest volume required }=\frac{\text { The total number of cells required }}{\text { Total cell count } / \mathrm{mL}}
$$

\subsection{Sample Preparation}

$5 \mathrm{mg}$ sample was tested solubility in DMSO. Then added $50 \mu \mathrm{l}$ DMSO and dissolved with the aid of a vortex. If not dissolved, add $50 \mu \mathrm{l}$ DMSO and diluted further with the help of vortex. Next, create variations in the concentration of the sample by means of diluting samples in DMSO using MK.

\subsection{Cytotoxic Test MTT Method}

To determine the toxicity of the sample, cells inserted into micro plate 96 -well with a density of $2 \times 10^{4}$ cells/wells, each
$100 \mu \mathrm{l}$ cells and observed the state of cells in a microscope. Cells were incubated in an incubator for 24 hours. At the end of incubation, the culture medium containing sample disposed and washed with $100 \mathrm{~mL}$ of PBS. Furthermore, on each of the wells was added $100 \mathrm{~mL}$ MK sample containing content with variations and incubated for 48 hours back. At the end of incubation, the culture medium containing the sample was removed and washed with $100 \mathrm{~mL}$ of PBS. Then into each of the wells was added $100 \mathrm{~mL}$ culture medium containing $5 \mathrm{mg} / \mathrm{ml}$ tetrazolium salt MTT (3-(4,5dimetiltiazol-2-yl)-2.5-difeniltetrazolium bromide) and 
incubated it back for 4 hours at a temperature $37{ }^{\circ} \mathrm{C}$. Living cell will react with MTT to form formazan colored purple. After 4 hours, pitting each stopper reagent is added $100 \mu \mathrm{L}$ SDS $10 \%$ in $0,1 \mathrm{~N} \mathrm{HCl}$ to kill the cells and dissolve the formazan crystals. Plate wrapped in aluminum foil and then incubated at room temperature in the dark for overnight. Furthermore, each pitting absorbance read with ELISA reader at a wavelength of $595 \mathrm{~nm}$.

\section{Results and Discussion}

Samples tested are products of curcumin analogues synthesized by different methods as shown in Table 1 . In Table 2 is data absorbance at a wavelength of $595 \mathrm{~nm}$ for T47D cells and media, Table 3 is a cytotoxic test results for all four samples with varying concentrations, LC spectra of the sample can be seen in Figure 1.

Table 1. Sample curcumin analog synthesis products.

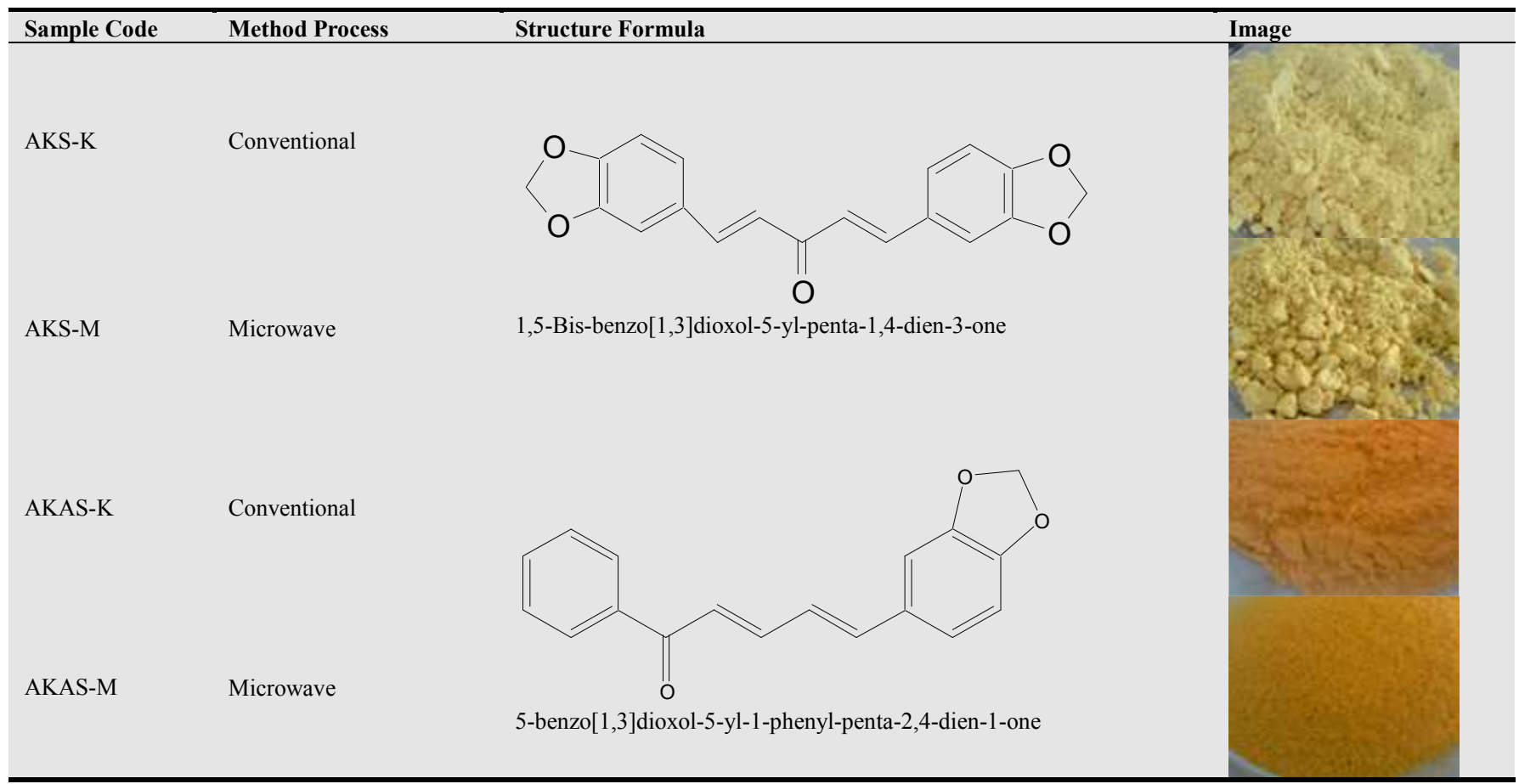

$B P I=>N R(8.00)$

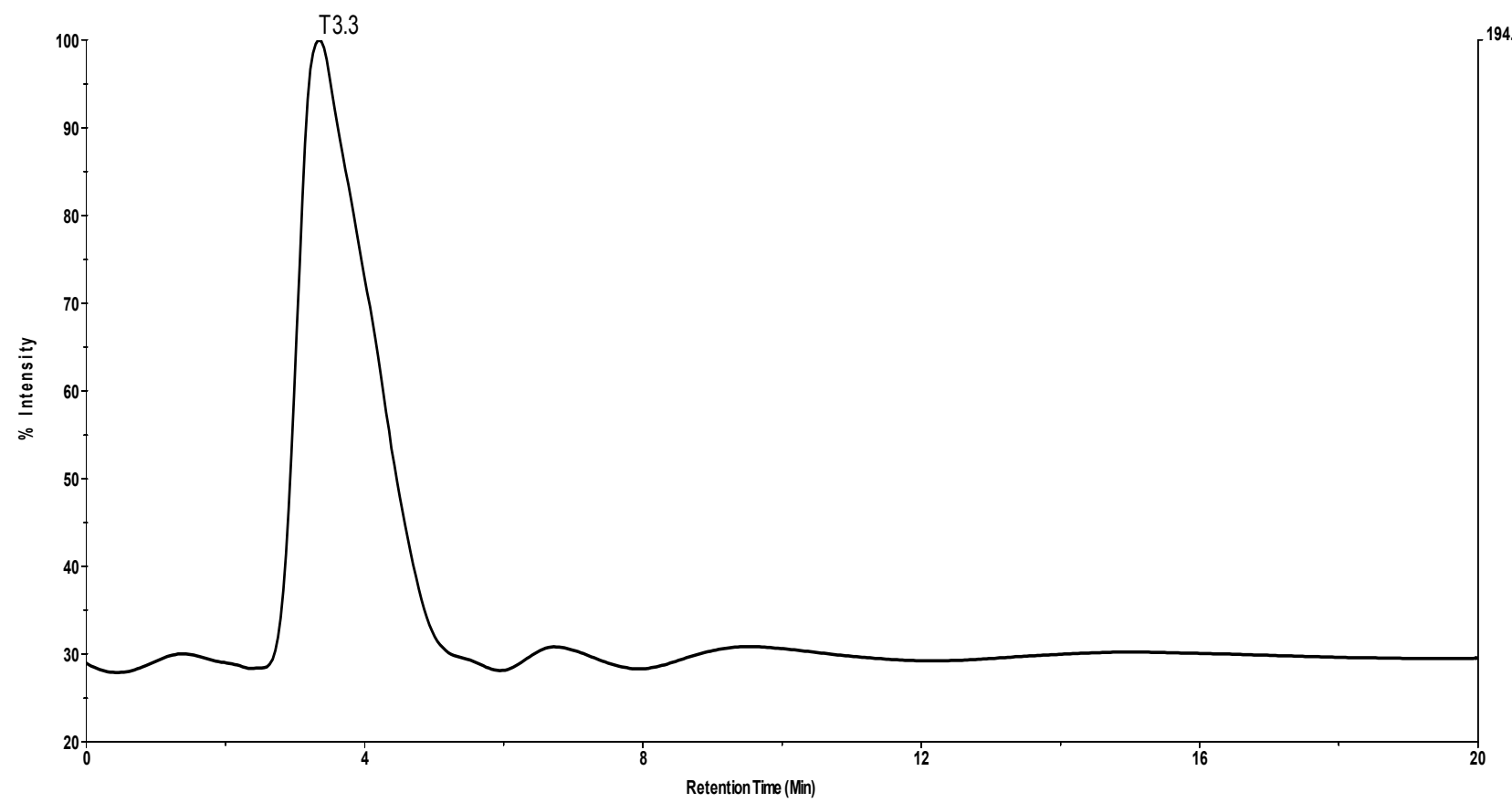




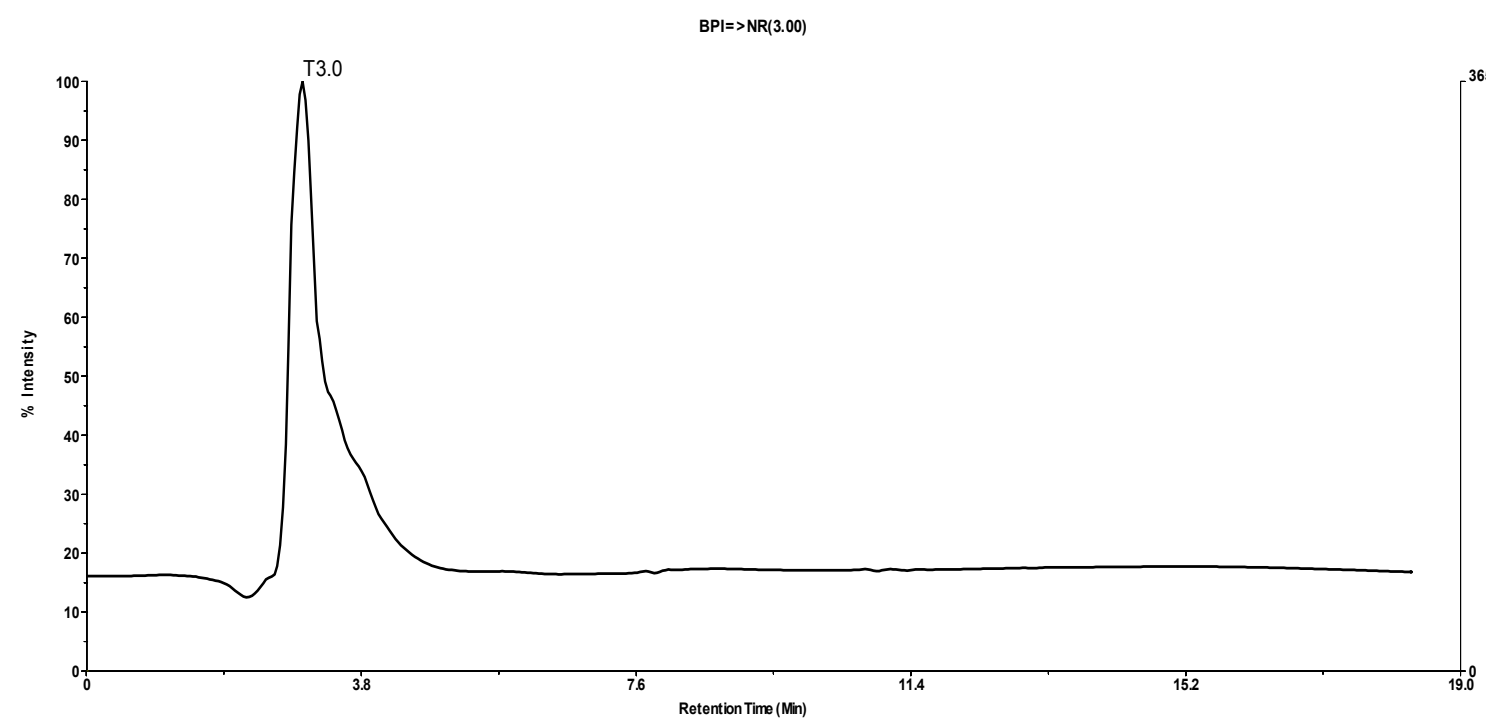

(b)

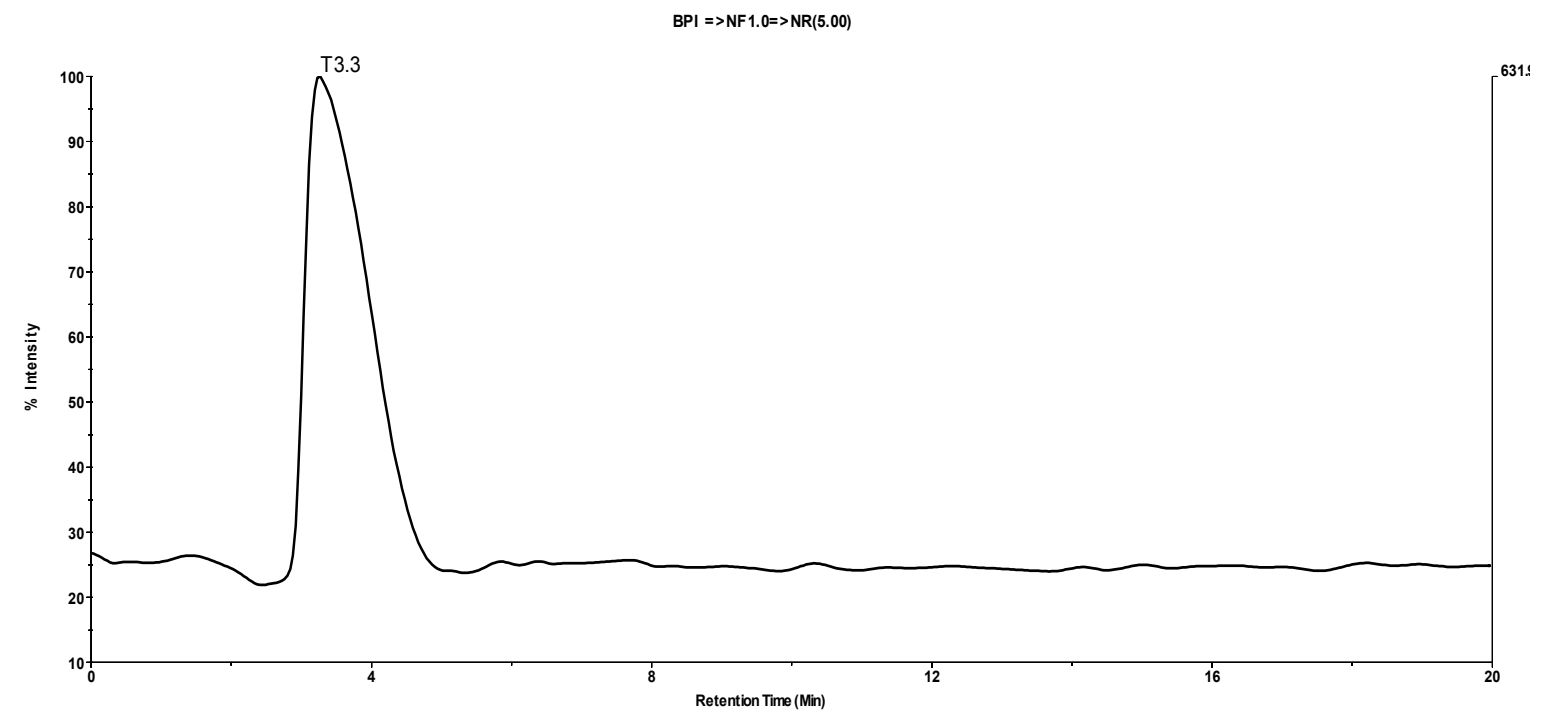

(c)

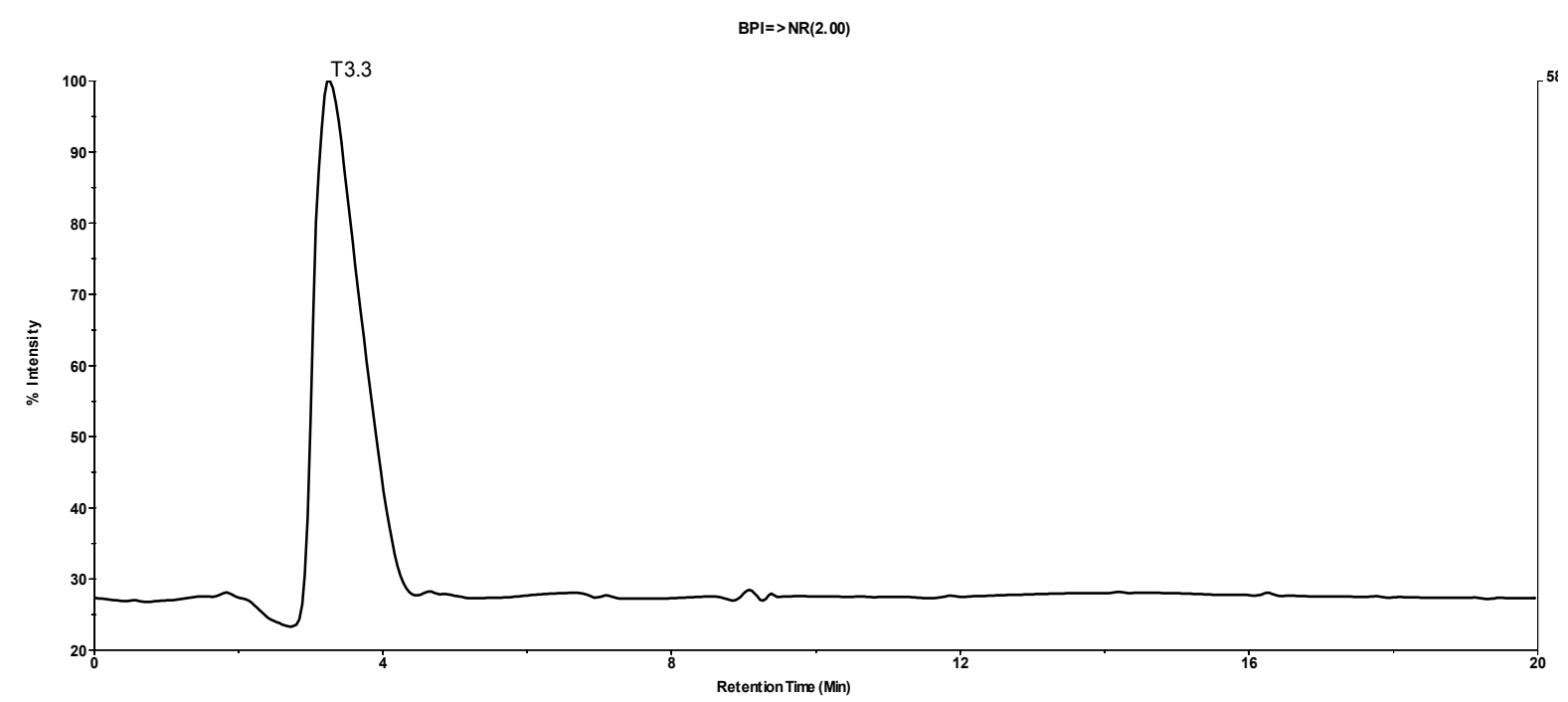

(d)

Figure 1. LC spktra a) AKS-K, b) AKS-M, c) AKAS-K, d) AKAS-M 
Table 2. Data absorbance control.

\begin{tabular}{lll}
\hline Control & Absorbance & Mean Absorbance \\
\hline \multirow{2}{*}{ Cells T47D } & 1,077 & 1,000 \\
& 1,053 & \\
\multirow{2}{*}{ Media } & 0,870 & 0,079 \\
& 0,080 & 0,077 \\
\hline
\end{tabular}

Table 3. Data cytotoxic T47D.

\begin{tabular}{|c|c|c|c|c|c|}
\hline \multicolumn{2}{|c|}{ Concentration $\mu \mathrm{g} / \mathrm{ml}$} & \multirow{2}{*}{$\begin{array}{l}\text { Absorbance AKS-K } \\
0,539\end{array}$} & \multirow{2}{*}{$\begin{array}{l}\text { Absorbance AKS-M } \\
0,493\end{array}$} & \multirow{2}{*}{$\begin{array}{l}\text { Absorbance AKAS-M } \\
0,300\end{array}$} & \multirow{2}{*}{$\begin{array}{l}\text { Absorbance AKAS-K } \\
0,408\end{array}$} \\
\hline \multirow{3}{*}{400} & 1 & & & & \\
\hline & 2 & 0,614 & 0,525 & 0,300 & 0,396 \\
\hline & 3 & 0,617 & 0,506 & 0,311 & 0,419 \\
\hline \multirow{3}{*}{200} & 1 & 0,650 & 0,575 & 0,455 & 0,464 \\
\hline & 2 & 0,660 & 0,553 & 0,470 & 0,470 \\
\hline & 3 & 0,735 & 0,557 & 0,429 & 0,419 \\
\hline \multirow{3}{*}{100} & 1 & 0,708 & 0,616 & 0,475 & 0,566 \\
\hline & 2 & 0,856 & 0,575 & 0,483 & 0,573 \\
\hline & 3 & 0,866 & 0,604 & 0,491 & 0,549 \\
\hline \multirow{3}{*}{50} & 1 & 0,876 & 1,046 & 0,580 & 0,575 \\
\hline & 2 & 1,047 & 1,037 & 0,549 & 0,580 \\
\hline & 3 & 1,078 & 1,011 & 0,599 & 0,558 \\
\hline \multirow{3}{*}{25} & 1 & 1,079 & 1,046 & 0,461 & 0,426 \\
\hline & 2 & 1,052 & 1,065 & 0,434 & 0,459 \\
\hline & 3 & 1,066 & 1,059 & 0,418 & 0,437 \\
\hline \multirow{3}{*}{12,5} & 1 & 0,812 & 1,039 & 0,453 & 0,593 \\
\hline & 2 & 1,010 & 1,093 & 0,465 & 0,634 \\
\hline & 3 & 1,029 & 1,047 & 0,471 & 0,549 \\
\hline
\end{tabular}

Data from table 3 are then analyzed to determine the $\mathrm{IC}_{50}$ value for each sample, the results can be seen in Figure 2 and table 4.

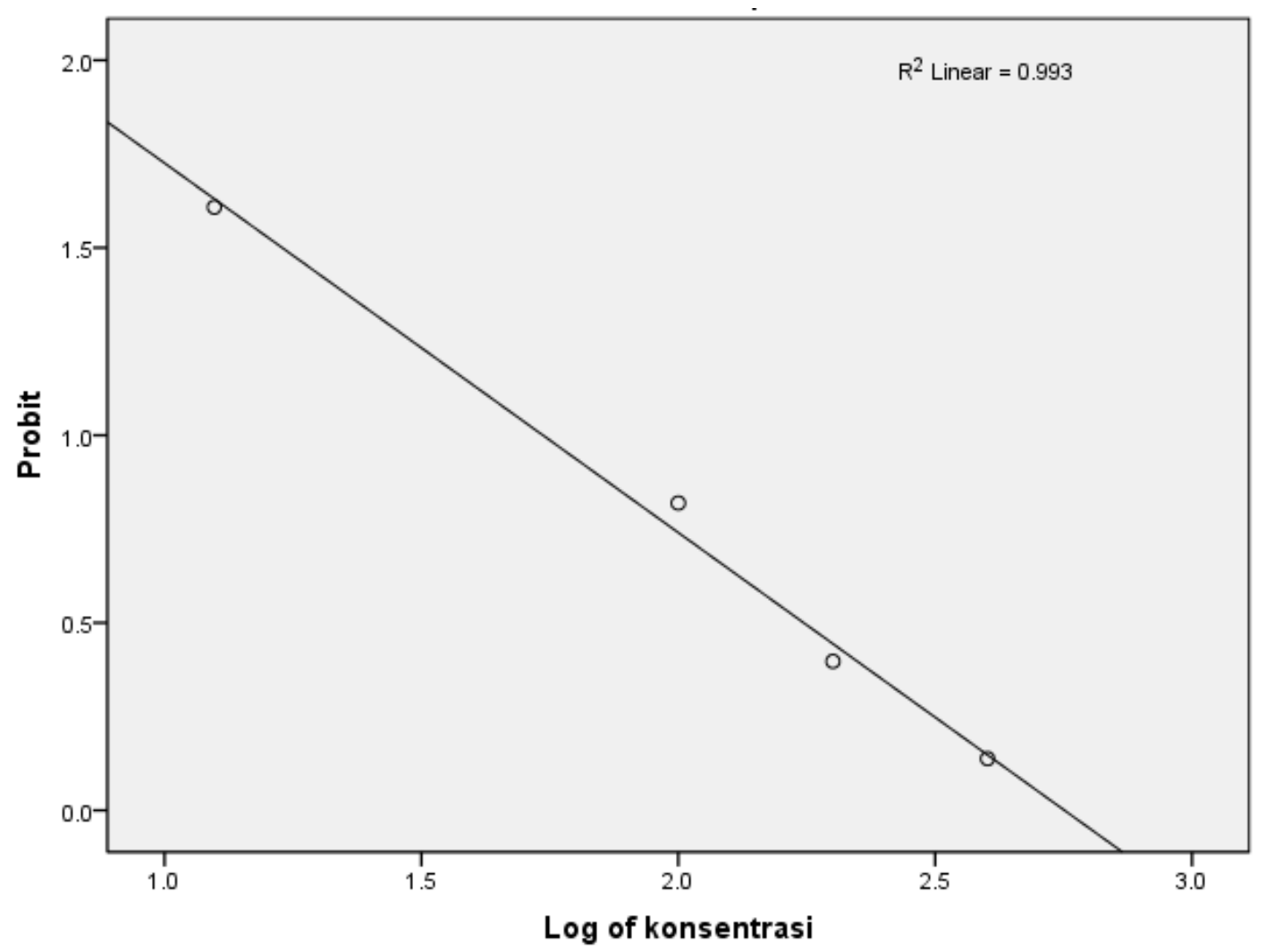

(a) 


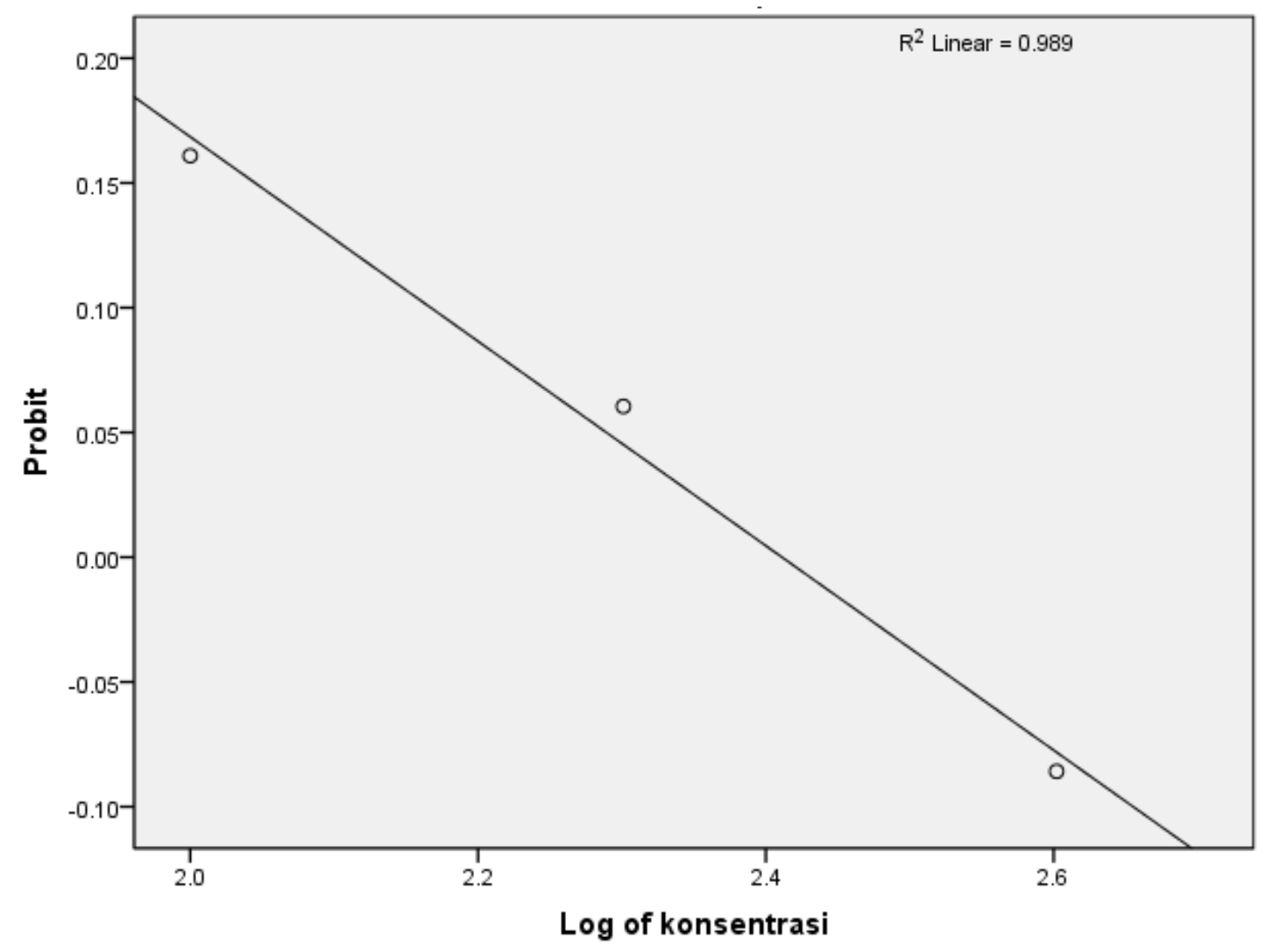

(b)

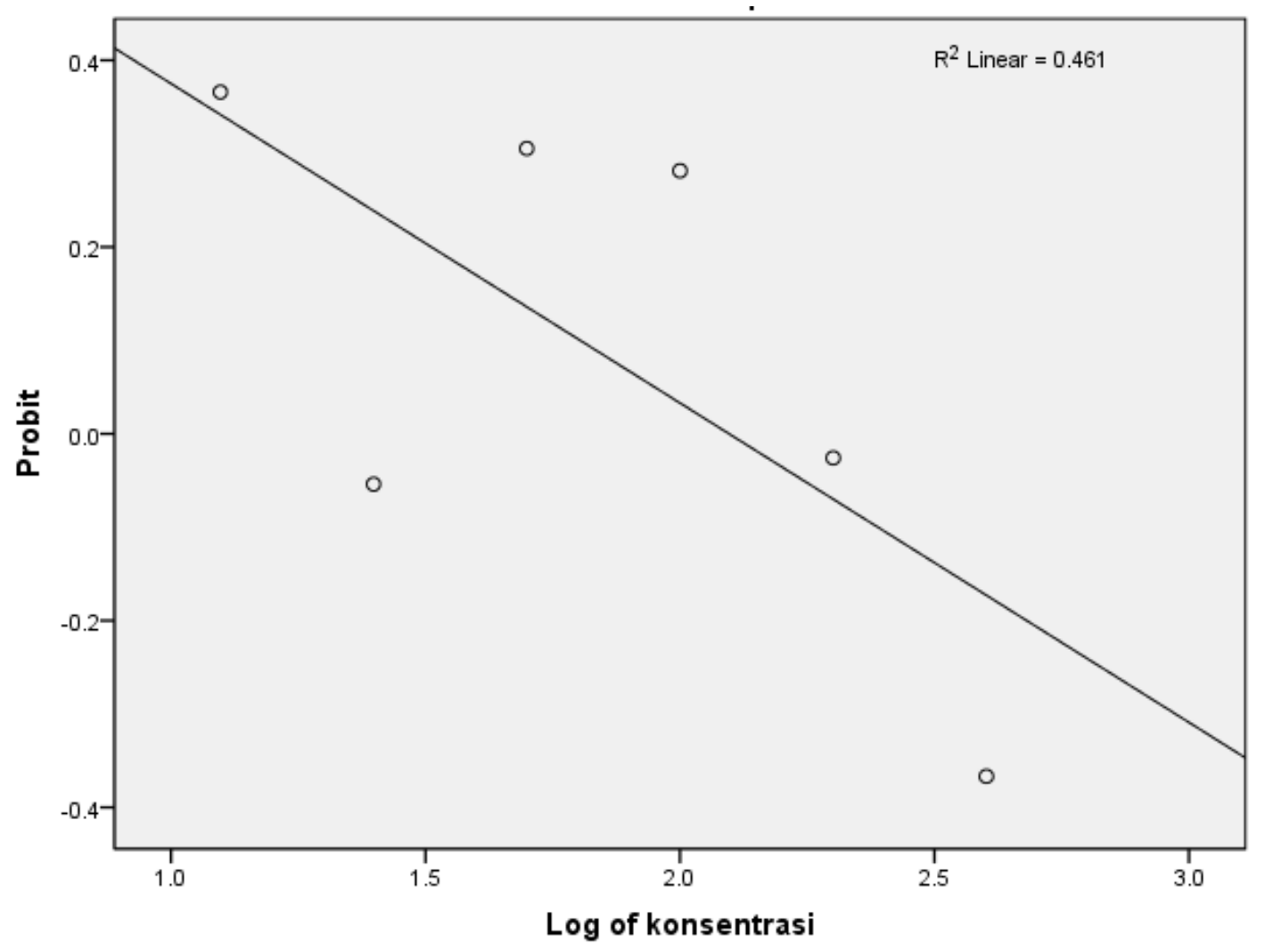

(c) 


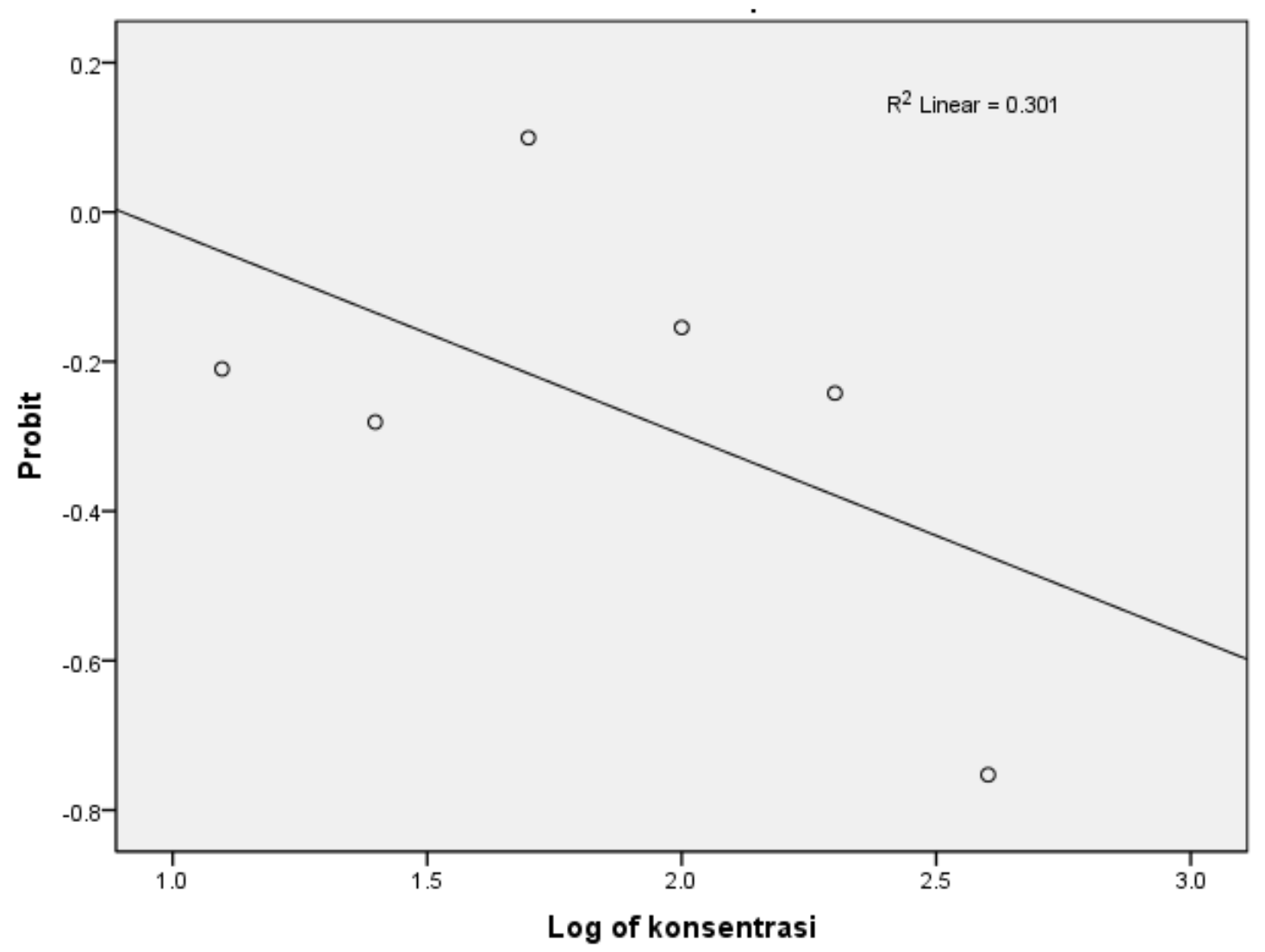

(d)

Figure 2. The graph probit transformed responses, a) AKS-K, b) AKS-M, c) AKAS-K, d) AKAS-M.

Table 4. Test results probit.

\begin{tabular}{ll}
\hline Product & $\mathbf{I C}_{\mathbf{5 0}} \boldsymbol{\mu} \mathbf{g} / \mathbf{m l}$ \\
\hline AKS-K & 555,276 \\
AKS-M & 257,798 \\
AKAS-M & 7,247 \\
AKAS-K & 125,300 \\
\hline
\end{tabular}

Viewed from both methods for the synthesis of the product 1,5-Bis-benzo[1,3]dioxol-5-yl-penta-1,4-dien-3-one and 5benzo[1,3]dioxol-5- yl-1-phenyl-penta-2,4-dien-1-one, the method gives the best results as an anti-cancer is a method of the microwave. The product AKS and AKAS product has the same 2 conjugation bond that allows the formed product isomers. Isomer product is formed and stabilized in the synthesis process using microwave provides anti-cancer effects against cancer cells T47D. Differences in the pharmacological activity of the two isomers can be very big, because this molecule functional groups apart at different distances in different isomer.

Mechanism of microwave heating is their agitation polar molecules or ions that move (Oscillate) due to the movement of magnetic or electrical fields. The existence of the field motion, so that the particles try to align the orientation or the terrain. The movement of the particles is limited by the limiting force (inter-particle interactions and electrical resistance), which restrain the movement of particles and resulting in random motion and heat. In the microwave heating, solvents and particles heated causing warming that evenly [19]. The mechanism of microwave heating is dipolar polarization, interfacial polarization, and conduction mechanism [20]. Melting points of these two methods are not too different, for sample akas-m $104^{\circ} \mathrm{C}$ while sample akas-k $111^{\circ} \mathrm{C}$; Melting point sample aks-m $180^{\circ} \mathrm{C}$ while sample aks$\mathrm{k} 191^{\circ} \mathrm{C}$. There are equations for microwave method, where for the second compound has a melting point lower than conventional methods. Product isomers formed and most stable during this process will last and the most dominant. The type of substituents, the position and orientation can affect the stability of the system [21].

\section{Conclusions}

Curcumin analog synthesis process provides an enormous influence on the activities of anti-cancer, although compounds have the same structure but can provide different activities depending on the isomer produced. The stability of the product during the process will produce the dominant product, from both samples aks and akas, the method that gives the best results is the microwave. Samples that give the best results is akas (5-benzo [1,3] dioxol-5-yl-1-phenylpenta-2,4-dien-1-one) by using microwave with $\mathrm{IC}_{50}$ values $7.247 \mathrm{ug} / \mathrm{ml}$, Microwave method produces a product with a lower melting point and provide the results of anti-cancer activity against breast cancer cells T47D. 


\section{References}

[1] Thomas S L, Jing Zhao, Zijian Li, Bin Lou, Yuhong Du, Jamie Purcell, James P. Snyder, Khuri F R, Liotta D, Fu H. 2010. Activation of the p38 pathway by a novel monoketone curcumin analog, EF24, suggests a potential combination strategy. Journal Biochemical Pharmacology. 80 (1309-1316)

[2] Moorthi C, Kathiresan K. 2013. Curcuminpiperine/curcumin-quercetin/ curcumin-silibinin dual drugloaded nanoparticulate combination therapy: a novel approach to target and treat multidrug-resistant cancers. Journal of Medical Hypotheses and Ideas. 7:15-20.

[3] Anand P, Bokyung S, Kunnumakkara AB, Kallikat N, Rajasekharan, Aggarwal BB. 2011. Suppression of proinflammatory and proliferative pathways by diferuloylmethane (curcumin) and its analogues dibenzoylmethane, dibenzoylpropane, and dibenzylideneacetone: Role of Michael acceptors and Michael donors. Journal Biochemical Pharmacology. 82:1901-1909.

[4] Anand P, Bokyung S, Kunnumakkara AB, Kallikat N, Rajasekharan, Aggarwal BB. 2011. Suppression of proinflammatory and proliferative pathways by diferuloylmethane (curcumin) and its analogues dibenzoylmethane, dibenzoylpropane, and dibenzylideneacetone: Role of Michael acceptors and Michael donors. Journal Biochemical Pharmacology. 82:1901-1909.

[5] Chandru.H, Sharada.A.C, Bettadaiah.B.K, Kumar.C.S.A, Rangappa.K.S, Sunila, Jayashree.K., 2007. In vivo growth inhibitory and anti-angiogenic effects ofvsynthetic novel dienone cyclopropoxy curcumin analogs on mouse Ehrlich ascites tumor Bioorganic \& Medicinal Chemistry 15 ( 76967703).

[6] Hahm ER, Gho YS, Park S, Park C, Kim KW, Yang CH. 2004. Synthetic curcumin analogs inhibit activator protein-1 transcription and tumor-induced angiogenesis. Biochemical and Biophysical Research Communications. 321:337-344.

[7] Labbozzetta M, Baruchello R, Marchetti P, Gueli MC, Poma P, Notarbartolo M, Simoni D, D’Alessandroa N. 2009. ChemicoBiological Interactions. 181:29-36.

[8] Anand P, Chitra S, Sonia J, Kunnumakkara AB, Aggarwal BB. 2008. Curcumin and cancer: An "old-age" disease with an "age-old" solution. Cancer Letters. 267:133-164.

[9] Liang G, Shao L, Wang Y, Zhao C, Chu Y, Xiao J, Zhao Y, Li X, Yang S. 2009. Exploration and synthesis of curcumin analogues with improved structural stability both in vitro and in vivo as cytotoxic agents. Journal Bioorganic \& Medicinal Chemistry. 17:2623-2631.

[10] Xiang YM, Li Y, Yin H, Zhang J. 2012. Curcumin: updated molecular mechanisms and intervention targets in human lung cancer. International Journal of Molecular Sciences. 13:39593978.

[11] Devasena T, Rajasekaran K N, Menon VP. 2002. Bis-1,7-(2hydroxyphenyl)-hepta-1,6-diene-3,5-dione (a curcumin analog) ameliorates dmh-induced hepatic oxidative stress during colon carcinogenesis. Pharmacological research. 46:1

[12] Srinivasan.M, Sudheer.A.R, Rajasekaran.K.N, Menon.V.P., 2008. Effect of curcumin analog on $\gamma$-radiation-induced cellular changes in primary culture of isolated rat hepatocytes in vitro. journal Chemico-Biological Interactions $176(1-8)$

[13] Zhao C, Yang J, Wang Y, Liang D, Yang X, Li X, Wu J, Wu X, Yang S, Li X, Liang G. 2010. Synthesis of mono-carbonyl analogues of curcumin and their effects on inhibition of cytokine release in LPS-stimulated RAW 264.7 macrophages. Journal Bioorganic \& Medicinal Chemistry. 18:2388-2393.

[14] Zhang Q, Zhong Y, Yan LN, Sun X, Gong T, Zhang ZR. 2011. Synthesis and preliminary evaluation of curcumin analogues as cytotoxic agents. Journal Bioorganic \& Medicinal Chemistry Letters. 21:1010-1014.

[15] Yin.S, Zheng.X, Yao.X, Wang.Y, Liao.D, 2013. Synthesis and Anticancer Activity of Mono-Carbonyl Analogues of Curcumin. Journal of Cancer Therapy 4 (113-123)

[16] Elavarasan S, Bhakiaraj D, Elavarasan T, Gopalakrishnan M. 2013. An efficient green procedure for synthesis of some fluorinated curcumin analogues catalyzed by calcium oxide under microwave irradiation and its antibacterial evaluation. Journal of chemistry. ID 640936.

[17] Nogrady Thomas. 1992. Kimia Medisinal. ITB, Bandung.

[18] Lüllmann Heinz, Hein Lutz, Mohr Klaus, Bieger Detlef. 2005. Color Atlas of Pharmacology. 3rd edition, revised and expanded. Thieme, Stuttgart, New York.

[19] Tellez HM, Alquisira JP, Alonso CR, Cortes JGL, Toledano CA. 2011. Comparative kinetic study and microwaves nonthermal effects on the formation of poly(amic acid) 4,4'(hexafluoroisopropylidene)diphthalic anhydride (6fda) and 4,4'-(hexafluoroisopropylidene)bis(-phenyleneoxy) dianiline (baphf). Reaction activated by microwave, ultrasound and conventional heating. Int. J. Mol. Sci. 12:6703-6721.

[20] Lam SS, Chase HA. 2012. A review on waste to energy processes using microwave pyrolysis. Energies. 5:4209-4232.

[21] Tori Motoo. 2015. Relative Stability of cis- and transHydrindanones. Molecules. 20:1509-1518. 